\title{
ANAESTHESIA FOR ELECTROCONVULSIVE THERAPY: A PSYCHIATRIC VIEWPOINT
}

\author{
Charles L. Rich and N. Ty Smith
}

\begin{abstract}
Brief general anaesthesia has added to the safety and comfort of electroconvulsive therapy (ECT). While usually a simple procedure, there are several areas in which ECT differs from other procedures requiring brief anaesthesia. These differences call for even more collaboration between psychiatrist and andesthetist than is customary. This revicw details the areas where the anaesthetic management may affect the outcome of ECT for both an individual treatment and a treatment series. These include the patient evaluation, the patient preparation, the sequence and doses of anaesthetic agents, and the recovery period. Because each patient receives a series of treatments, an optimum regimen from both the psychiatric and anaesthetic standpoints can ultimately be achieved.
\end{abstract}

Key Words: ANAESTHESIA, electroshock.

IT HAS BEEN FORTY YEARS since the advent of electrically induced grand mal seizures as a treatment in psychiatry. Modification of the treatment process, improvement in the anaesthetic care, and greater attention to preparation for emergencies have resulted in a high level of safety for electroconvulsive therapy (ECT). Several large series in the past ten years (totaling over 35,700 treatments) have reported no clear direct mortality or fractures. ${ }^{1-4}$ The one reported death was described as "... having doubtful relationship to the ECT."'3

Many psychiatrists continue to administer both the anaesthetic and the treatment itself, but there are growing pressures to divide the functions between the appropriate specialists. Definitions of hospital staff privileges as well as potential liability issues have accelerated this trend. Also, since some training programs no longer teach psychiatric residents to administer anaesthesia, a growing number of psychiatrists are inadequately prepared for that. For these reasons, anaesthetists are being called upon more frequently to administer anaesthetics for ECT. We feel this should be routine where anaesthetic services are available. Certainly, any psychiatrist who does

Charles L. Rich, M.D. Assistant Professor of Psychiatry in Residence, University of California at San Diego; Staff Psychiatrist, San Diego Veterans' Administration Medical Center; N.T. Smith, M.D., Professor of Anesthesiology, University of California at San Diego; Staff Anesthesiologist, San Diego Veterans' Administration Medical Center.

Address correspondence to Dr. Rich at the Veterans' Administration Medical Center (116A), 3350 La Jolla Village Drive, San Diego, California 92161, U.S.A.

Canad. Anaesth. Soc. J., vol. 28, no. 2, March 1981 administer the anaesthetic must be able to demonstrate sufficient knowledge and skills to qualify for hospital privileges in this area.

The technical aspects of anesthesia for ECT seem straight forward and are of relatively minor complexity in an anaesthetist's overall practice. There are four issues which should command particular attention from anaesthetists, however. First, while only a short time period is involved, ECT is unique when compared to other medical procedures requiring brief anaesthesia. Second, both the physiological and psychological aspects of the anaesthetic process itself may influence actual treatment outcome. Third, because of the possible effect of anaesthesia on ECT outcome and the relative brevity of the treatment itself, more preliminary and on-the-spot coordination between anaesthetists and psychiatrists is necessary. Fourth, since the procedure is repetitive, an optimum anaesthetic regimen can be sought for each patient. This article will review these aspects of anaesthesia for ECT, divided into the three logical parts: the preparation for treatment, the treatment itself, and the recovery period.

\section{Treatment Preparation}

As in any procedure, fear of the first treatment will usually be the most intense. While obliged to explain the risk/benefit aspects in obtaining consent, both the psychiatrist and anaesthetist should seek to be as reassuring as possible. $\mathrm{Pa}$ tients selected for ECT are often delusional and may either express a wish to die from the treatment or a fear of being killed by the treatment. 
Because of the brief nature of the anaesthetist's involvement with the patients, he/she should probably avoid discussing the patient's psychiatric illness during the pretreatment evaluation. Any question the anaesthetist may have regarding the concurrent administration of "psychotropic" medication during the course of ECT should be discussed with the psychiatrist before beginning the series of treatments.

Electroconvulsive therapy has been given successfully to patients with rather serious concurrent medical problems (e.g. severe heart disease, ${ }^{5,6}$ late pregnancy, ${ }^{7}$ glaucoma ${ }^{8}$ ). These situations might call for individual modification in the anaesthetic and treatment process. Such cases should be discussed in advance by the anaesthetist, medical consultant and psychiatrist, to plan an optimal course balancing safety and the efficacy of the treatment. For example, a patient with a recent fracture may require total paralysis to protect against convulsive muscle activity. The psychiatrist may then wish to use EEG monitoring or tourniquet occlusion of a limb to be sure that the patient has a seizure. In fact, some authors recommend the use of EEG monitoring as a regular procedure to assure the adequacy of seizure induction. ${ }^{9}$

Pre-treatment sedation is usually not necessary and may unnecessarily prolong the recovery period. The psychiatric ward staff should be trained in reassuring patients and keeping them calm. If the psychiatrist does order a pretreatment sedative, he should inform the anaesthetist at treatment time.

Patients must be kept fasting for six or more hours before the treatment to minimize the risk of vomiting during or after the treatment. They must be watched closely during the fasting period to avoid the surreptitious ingestion of food or fluids. Most psychiatrists prefer to give treatments in the early morning to minimize the fasting period. The patients are then able to participate in routine daily activities, reassuring them that they are not somehow worse off than those not receiving ECT. They are also able to have a normal breakfast. This is particularly important in improving and maintaining the nutrition and hydration of patients who, by the nature of their illnesses, have poor appetite and may be physically debilitated.

There is no way to totally avoid the frightening aspects of a well-equipped treatment room. Attention should be paid, therefore, to facilitating the rapid, but appropriately cautious, progress towards the anaesthetic induction. Establishing

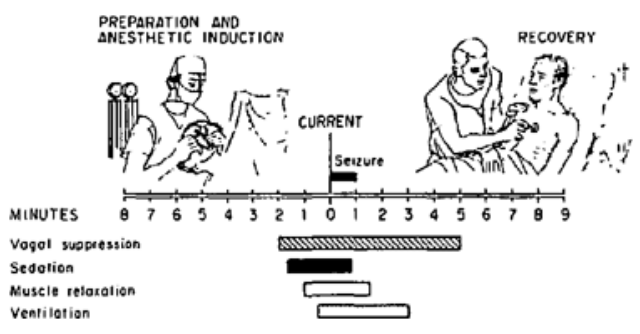

Figure 1 Stages of ECT and Anaesthesia. The times for the stages of the ECT treatment are indicated above the line in minutes. These include preparation and anaesthetic induction (approximately five to ten minutes), passage of the current (approximately one second), seizure (approximately one minute), and recovery (approximately five to ten minutes). Below the line are the approximate times for the elements of anaesthesia. These include vagal suppression (seven minutes), sedation (two minutes), muscle relaxation (two minutes), and ventilation (four minutes).

an intravenous infusion line and any monitoring devices before the patient enters the treatment room will help to minimize the pre-induction time required in the treatment area.

\section{The Treatment}

The major goals of anaesthesia for ECT are to prevent complications of the treatment - vagal induced oropharyngeal secretions and bradycardia, fear and discomfort from the induction of the seizure, fractures, and hypoxia. This is somewhat more complicated than brief anaesthesia for most "minor" procedures.

Optimal results require close cooperation between the psychiatrist and anaesthetist, both in the timing of the treatment and in the individual adjustment of the agents involved. Figure 1 shows the specific phases of an electroconvulsive treatment. The phases of anaesthesia involved are also indicated. It can be seen that the total time for the treatment can be quite brief. (A few investigators have described the use of multiple seizures during a treatment session, but this is not widely practised and will not be considered here.) Likewise, the time of action needed for each of the elements of anaesthesia is brief and covers a specific portion of the treatment process.

Vagal suppression is used to decrease the secretions and reflex bradycardia associated with a seizure. ${ }^{2}$ Whether the use of atropine actually decrsases treatment morbidity and/or mortality is uncertain. Most authorities recommend its use, however, recognizing that possible complications of atropine must be anticipated. Giving atropine intravenously one to two minutes before 
the hypnotic agent works as well as subcutaneous administration 30 to 45 minutes before the treatment. ${ }^{10}$ The intravenous route allows more time flexibility, while avoiding the discomfort of a subcutaneous injection and slow build-up of annoying anticholinergic effects such as thirst. A patient who sneaks a large drink of water before ECT presents an added and unexpected risk. If the anaesthetist elects to avoid atropine, he/she should be prepared to manage possibly severe bradycardia and/or secretions.

Any of a variety of standard anaesthetic agents may be used to induce sleep. Ensuring maximum patient comfort by providing rapid induction and rapid post-ictal recovery of consciousness is one goal. It is important to reduce any antagonistic effects on seizure activity: to a minimum because of the possible relationship between total seizure time and treatment efficacy. ${ }^{9}$ Some central nervous system depressant drugs (e.g. lidocaine, procaine ${ }^{11}$ ) decrease electrically induced seizure length but, perhaps more importantly, some agents, for example certain barbiturates ${ }^{12}$ and benzodiazepines ${ }^{13}$ may raise the seizure threshold (see below). A "missed treatment" resulting from the inability to induce a seizure not only deprives the patient of the therapeutic benefit, but also increases the risk by requiring further treatment sessions. Further research is needed to clarify these issues, but it seems reasonable to keep the dose of any induction agent to a minimum on the basis of existing information. Methohexitone is said to be more desirable than thiopentone, ${ }^{14}$ a benzodiazepine (diazepam) ${ }^{2.15}$ or other non-barbiturate agents (ketamine, ${ }^{16}$ propanidid, ${ }^{2,17}$ alphaxalone/alphadalone, ${ }^{18.19}$ in terms of time for recovery of consciousness. Methohexitone has also been shown in some studies to be associated with fewer postconvulsive ECG abnormalities. ${ }^{14.15}$ Etomidate has been found comparable to alphaxalone/alphadalone, but has not been compared to methohexitone. ${ }^{20} \mathrm{~A}$ reasonable starting dose for methohexitone is $0.75 \mathrm{mg} \cdot \mathrm{kg}^{-1}$ of body weight. ${ }^{21}$ This can be adjusted up or down for subsequent treatments according to individual patient response. Although either ketamine or dizepam would be reasonable substitutes in the face of barbiturate allergy, diazepam would probably be preferable because of the high frequency of side effects during recovery from ketamine. Diazepam has been observed to increase the threshhold for electrically induced seizures (in doses up to $60 \mathrm{mg}$ intravenously) so this should be considered when using it as an induction agent. ${ }^{13}$
Finally, because of the irritant properties of methohexitone in solution, use of a larger vein (e.g. anticubital) might result in less injection discomfort and better patient acceptance.

The use of succinylcholine chloride has virtually eliminated the risk of fractures related to ECT. An optimal dose will adequately attenuate the muscle contractions and yet allow the psychiatrist to determine if the patient is having a seizure. The time until recovery of spontaneous ventilation should also be kept to a minimum. One study suggested that $0.5 \mathrm{mg} \cdot \mathrm{kg}^{-1}$ is a satisfactory initial dose which may be adjusted for subsequent treatments. ${ }^{22}$ Several studies have shown that succinylcholine may be injected immediately after the hypnotic agent without untoward effects. ${ }^{14.21-23}$ This may also shorten the overall treatment time. The small percentage of patients with significant plasma cholinesterase deficiency can be detected clinically at the time of the first treatment by injecting a small test dose (3 $\mathrm{mg}$ ) of succinylcholine. Abolition of the knee jerk is evidence of inadequate plasma cholinesterase levels. ${ }^{24}$ If the knee jerk is abolished, the treatment may be given with the expectation of adequate relaxation. Plasma cholinesterase levels might be assayed prior to the next treatment, but, basically, determination of the dose/response curve must be determined individually for each patient. ${ }^{25}$ Although nondepolarizing agents could be used, they offer no advantage over a properly titrated dose of succinylcholine. If prolonged apnoea does occur, it is probably wise to further sedate the patient until spontaneous ventilation returns. The fear of paralysis is something patients may remember clearly even from their post-ictal confusional state.

Provision of proper ventilation during the apnoeic period is essential. Some patients do object to (or fear) the placing of a mask over the face before going to sleep. Since the seizure may be induced almost immediately after the cessation of spontaneous breathing (approximately $45 \mathrm{sec}$ onds after the injection of succinylcholine), it could be argued that ventilatory assistance may not be necessary until after the seizure is completed; about another 30 to 45 seconds. On the other hand, there is evidence that hyperventilation with oxygen before and during the seizure can lengthen the seizure activity. ${ }^{26}$ Although further research is necessary to decide whether this is a significant variable in ECT efficacy, until proven otherwise it would seem reasonable to use hyperventilation. 


\begin{tabular}{|c|c|c|c|c|c|c|c|c|c|}
\hline $\begin{array}{l}\text { Treat- } \\
\text { ment } \\
\text { Number }\end{array}$ & Date & Time & Atropine & $\begin{array}{l}\text { Anesthesio } \\
\text { Metho- } \\
\text { hexital }\end{array}$ & $\begin{array}{l}\text { Succinyl- } \\
\text { choline }\end{array}$ & Voltage & Treatmen & $\begin{array}{l}\text { Electrode } \\
\text { Placement }\end{array}$ & Weight $175 \mathrm{lb} .=80 \mathrm{~kg}$. \\
\hline 1 & & & $1.0 \mathrm{mg}$. & $60 \mathrm{mg}$. & $40 \mathrm{mg}$. & 150 & $\begin{array}{l}1.0 \\
\text { sec. }\end{array}$ & $\mid \begin{array}{c}\text { Right } \\
\text { Unilateral }\end{array}$ & $\begin{array}{l}\text { 1) Excess secretions } \\
\text { 2) Minimal seizure activity, } \\
\text { prolonged apnea }\end{array}$ \\
\hline 2 & & & $1.5 \mathrm{mg}$. & $60 \mathrm{mg}$. & $35 \mathrm{mg}$. & 150 & $\begin{array}{l}1.0 \\
\text { sec. }\end{array}$ & & $\begin{array}{l}\text { 1) No secretions } \\
\text { 2) Apnea still a little long }\end{array}$ \\
\hline 3 & & & $1.5 \mathrm{mg}$. & $60 \mathrm{mg}$. & $30 \mathrm{mg}$. & $\frac{150}{160}$ & $\begin{array}{l}1.0 \\
\text { sec. } \\
1.0 \\
\text { sec. }\end{array}$ & & $\begin{array}{l}\text { 1) Good relaxation, } \\
\text { minimal apnea } \\
\text { 2) No seizure first shock }\end{array}$ \\
\hline 4 & & & $1.5 \mathrm{mg}$. & $60 \mathrm{mg}$. & $30 \mathrm{mg}$. & 160 & $\begin{array}{l}1.0 \\
\text { sec. }\end{array}$ & & Took somewhat long to wake up \\
\hline 5 & & & $1.5 \mathrm{mg}$. & $55 \mathrm{mg}$. & $30 \mathrm{mg}$. & 160 & $\begin{array}{l}1.0 \\
\text { sec. }\end{array}$ & & Good \\
\hline
\end{tabular}

FiguRE 2 Sample Sequential ECT Record. A series of five consecutive treatments are displayed. Anaesthesia and treatment variables are recorded for each treatment with observations on the treatment process suggesting modifications in the regimen. Changes in the anaesthesia (atropine, methohexit succinylcholine) and treatment (voltage, length of stimulus, electrode placement) variables are recorded showing development of an optimum regimen.

Proper modification of the anaesthetic doses and timing requires cooperation between the anaesthetist and psychiatrist. It is helpful to use a consecutive-treatment form to record sequential anaesthetic and treatment variables, particularly if the same physicians are not present for each treatment. Figure 2 shows a sample of such a flow sheet with examples of entries demonstrating sequential modifications.

\section{RECOVERY}

When spontaneous ventilation has returned, the patient should be turned on his/her side to protect against possible aspiration of vomitus or excessive secretions. Excessive stimulation of the patient should be avoided so as not to cause agitation in the immediate postictal phase. Although pre-medication with haloperidol or diazepam may prevent severe post-treatment agitation, ${ }^{27}$ it usually can be avoided by staff skilled in managing this brief problem. As discussed earlier, potentially adverse effects of using extra medication need to be considered. Patients should be observed closely with resuscitation equipment nearby for about 15 minutes after the seizure, since this is a high risk period for sudden death even in patients with previously unsuspected heart disease. ${ }^{28}$

\section{CONCLUSION}

The anaesthetic process, albeit brief, plays an important role in determining the efficacy of electroconvulsive therapy. The recent American Psychiatric Association Task Force Report on ECT correctly points out that there are variations in the anaesthetic technique which may be acceptably safe and effective. ${ }^{29}$ These variations should, however, take into account currently available knowledge about the effects of anaesthesia on ECT.

Attention to patient comfort is essential in maintaining compliance throughout a series of treatments. Fear of the treatment itself (particularly the first one), the imposing complexity of the treatment setting, the use of a face mask, and the possibility of paralysis while awakening are important to anticipate and accommodate when they occur.

The anaesthetic agents used may have an effect on the successful induction of seizure activity necessary for therapeutic effectiveness. Since each patient receives a series of treatments, there 
is an opportunity for each anaesthetic agent to be modified for its optimum effect. Close cooperation and timing between the anaesthetist and psychiatrist are required for optimum treatment performance.

\section{REFERENCES}

I. Pirts, F.N. JR. Medical aspects of ECT. Semin Psychiatry 4: 27 (1972).

2. McCleaye, D.J. \& Blackemore, W.B. Anesthesia for electroconvulsive therapy. Anesth. Intensive Care 3: 250 (1975).

3. Heshe, J. \& RoEder, E. Electroconvulsive therapy in Denmark. Br, J. Psychiatry 128: 241 (1976).

4. Turek, I.S. \& Hanlon, T.E. The effectiveness and safety of electroconvulsive therapy (ECT). J. Nerv, Ment. Dis. 164: 419 (1977).

5. AtKinson, R.M. \& Rubin, R.T. Electroconvulsive treatment and severe cardiovascular disease. Am. J. Psychiatry 12I: 249 (1964).

6. Pilling, L.F., Barry, M.J. JR. \& Parkin, T.W. Electroshock therapy of a depressed patient with complete heart block. Am. J. Psychiatry 119:788 (1963).

7. Levine, R. \& Frost, E.A.M. Arterial blood-gas analyses during electroconvulsive therapy in a parturient. Anesth. Analg. 54: 203 (1975).

8. Epstein, H.M., Fagman, W., Bruce, D.L. \& A RRAM, A. Intraocular pressure changes during anesthesia for electroshock therapy. Anesth. Analg. 54: 479 (1975)

9. Maletsky, B.M. Seizure duration and clinical effect in electroconvulsive therapy. Compr. Psychiatry 19: 541 (1978)

10. Clement, A.J. Atropine premedication for electric convulsion therapy. Br. Med. J. Jan. 27. pp. 228-229 (1962).

11. Wikinski, J., Usubiaga, J.E., Morales, R.L., TorriekI, A. \& Usubiaga, L.E. Mechanism of convulsions elicited by local anesthetic agents: I. Local anesthetic depression of electrically induced seizures in men. Anesth. Analg. 49-504 (1970).

12. Fink, M. Convulsive Therapy. Theory and Practice. New York: Raven Press (1979). p. 211.

13. WAtson, A.C. Diazepam in convulsive therapy, in Diazepam in Anesthesia. Edited by P.F. Knight \& C.G. Burgess. Bristol: John Wright and Sons, Ltd. (1968). pp. 77-81.

14. Pitts, F.N. Jr., Desmarias, G.M., Stewart, W. \& SCHABERG, K. Induction of anesthesia with methohexital and thiopental in electroconvulsive therapy. N. Engl. J. Med. 273: 353 (1965).
15. Allen, R.E. \& PitTs, F.N. JR. Drug modification of ECT: Methohexital and diazepam. Biol. Psychiatry 14:69 (1979).

16. MCINNES, E.J. \& JAmES, N.M. A comparison of ketamine and methohexital in electroconvulsive therapy. Med. J. Aust. 1: 1031 (1972).

17. Rollason, W.N., Sutherland, M.S. \& Hall, D.J. An evaluation of the effect of methohexitone and propanidid on blood pressure, pulse rate and cardia arrhythmia during electroconvulsive therapy. Br. J. Anaesth. 43: 160(1971).

18. Foley, E.I., Walton, B., Savege, T.M., StruNIN, L. \& SIMPSON, B.R. A comparison of recovery times between Althesin and methohexitone following anaesthesia for electroconvulsive therapy. Postgrad. Med. J. June suppl. (1972). p. 112-115.

19. CoOPER, J. Althesin in out-patient psychiatric practice. Postgrad. Med. J. June suppl. (1972). pp. 115-116.

20. O'Carroll, J.M., Blogg, C.E. \& Hoinyille, T.M. Etomidate in electroconvulsive therapy. Anaesthesia 32: 868 (1977).

21. Witztum, J., BAker, M., WOOdruff, R.A. JR., \& PITTS, F.N. JR. Electrotherapy: The effects of methohexital on EKG. Dis. Nerv. Syst. 31: 193 (1970).

22. Pitts, F.N. JR., Woodruff, R.A. Jr., Craig, A.G. \& Rich, C.L. The drug modification of ECT. II. Succinylcholine dosage. Arch. Gen. Psychiatry 19: 595 (1968).

23. WoOdrufF, R.A. JR., Pitrs, F.M. JR. \& MCCLuRE, J.N. JR. The drug modification of ECT. I. Methohexital, thiopental, and preoxygenation. Arch. Gen. Psychiatry 18:605 (1968).

24. Impastato, D.J. Tendon reflexes as a guide to the safe use of succinylcholine in medicine. Can. Psychiatr. Assoc. J. 11:567 (1966).

25. Lee-Son, S., Pilon, R.N., Nahor, A.\& Waud, B.E. Use of succinylcholine in the presence of atypical cholinesterase. Anesthesiology 43: 493 (1975).

26. Holmberg, G., Hard, G. \& Ramouist, N. Experiments in the prolongation of convulsions in duced by electric shock treatment. Acta Psychiat. Neurol. Scad. 3/: 61 (1956).

27. Gomez, J. \& Dally, P. Intravenous tranquillization with ECT. Br. J. Psychiatry 127: 604 (1975).

28. Barker, J.C. \& Baker, A.A. Deaths associated with electroplexy. J. Ment. Sci. 105: 339 (1959).

29. Task Force on Electroconvulsive Therapy: Electroconvulsive Therapy. Washington: American Psychiatric Association (1978).

\section{RÉSUMÉ}

L'administration d'une anesthésie générale de courte durée a rendu la sismothérapie à la fois sécuritaire et confortable pour les malades. Bien qu'il s'agisse d'une procédure simple, la thérapie par électrochoc diffère en plusieurs points des autres procédures requiérant une anesthésie de courte durée et nécessite une grande collaboration entre les psychiatres et les anesthésistes. Ce travail rappelle les points importants de la conduite anesthésique qui peuvent avoir une influence sur les résultats du traitement, à savoir: l'évaluation et la préparation des patients, l'administration et le dosage des anesthésiques, ainsi que la phase d'émergence de l'anesthésie. Comme chacun des malades reçoit une série de traitements, on peut en arriver dans chaque cas à une méthode optimal tant pour l'anesthésiste que pour le psychiatre. 